\title{
DESAFIOS IMINENTES PARA PROJETOS DE FORMAÇÃO DE PROFISSIONAIS PARA EDUCAÇÃO INFANTIL
}

\author{
MARIA LUCIA DE A. MACHADO \\ Pesquisadora da Fundação Carlos Chagas
}

\begin{abstract}
RESUMO
O propósito deste texto éo de apontar desafios iminentes para formuladores e implementadores de projetos de formação de profissionais para educação infantil a partir de duas das várias vertentes que os subsidiam. Aborda-se inicialmente um conjunto de fatores que configura o contexto atual brasileiro no qual os projetos se realizam. Em seguida, trata-se da concepção de crescimento e desenvolvimento infantil da qual decorre o desafio de integrar o enfoque cuidarleducar à ênfase numa pedagogia calcada nas interações de crianças e adultos, resultando em temas específicos de formação. Sabendo da força com que um modelo de escolarização caricato vem se difundindo nas instituições de atendimento a crianças de 0 a 6 anos, outro dos desafios que se coloca aos projetos de formação é o de formar profissionais aptos a integrarem-se aos sistemas educacionais e, simultaneamente, atuarem em modalidades de atendimento sustentados em aportes teóricos fundamentados de modo consistente nas necessidades e características de crescimento e desenvo/vimento de bebês e crianças pequenas.

EDUCAÇÃOINFANTIL - FORMAÇÃOPROFISSIONAL - PROFISSIONAISDEEDUCAÇÃOINFANTIL
\end{abstract}

\section{ABSTRACT}

CHILDEDUCATIONPROFESSIONALS: IMMINENT CHALLENGESFOR TRAININGPROJECTS. The premise of this text is to point out the imminent challenges for those who formulate and implement training projects for child education professionals, based on two of the several currents which support them. The first includes the group of factors that make up the present Brazilian context in which projects are undertaken. The second, treats the conception of growth and child development from which comes the challenge to integrate the focus care/ education, emphasizing a pedagogy based in child adult interaction, resulting in specific training themes. Knowing of the force with which a caricatured model of schooling has been disseminated in the institutions that care for children from birth to 6 years of age, another challenge put to training projects is to form professionals able to integrate themse/ves into the educational systems and simultaneously to act in accord with care modalities consistent with the needs and characteristics of growth and development of babies and small children.

Versão baseada em trabalho apresentado na mesa-redonda O profissiona/ de educação infantil e sua formaçãono I Congresso Paulista de Educação Infantil/Copedi em Águas de Lindóia, São Paulo, em outubro de 1998. A pesquisa é fruto de investigações apresentadas em tese de doutorado defendida na PUC-SP, em 1998. 


\section{APRESENTAÇÃO}

Tarefas de diferentes naturezas são desempenhadas pelos responsáveis por projetos de formação de profissionais para a educação infantil durante as fases de idealização, planejamento ou implementação das diferentes iniciativas. Em uma perspectiva de currículo que se deseja avançada não é suficiente delimitar unidirecionalmente disciplinas e conteúdos para a formação específica para o trabalho com crianças pequenas, visto que à exigência de formar o profissional num sentido amplo adiciona-se a de corresponder a expectativas de alunas e alunos, seja incorporando experiências e saberes prévios, seja suprindo demandas identificadas como relevantes (Evans, 1982; Domingues, 1988; Moreira, 1995; Apple, 1994; Moreira, Silva, 1994; Machado, 1994; Machado, 1996, 1996a, 1996b).

Sendo assim, observa-se que diferentes planos de ação se interseccionam nos projetos, incidindo ora sobre temas implícitos para atuação futura dos profissionais em formação, ora incorporando necessidades e possibilidades dos sujeitos envolvidos (professores e estudantes), contemplando elementos presentes nos contextos institucionais em que os projetos se realizam, e ainda incluindo os processos de acompanhamento e aprimoramento propriamente ditos.

Se diferentes referências são necessárias para a formulação de projetos de formação que se pretendam consistentes, sublinha-se que a finalidade precípua dos projetos é a de habilitar docentes e não docentes para atuar junto a crianças de 0 a 6 anos em contextos coletivos tais como creches, pré-escolas e centros de educação infantil, instituições que vêm se integrando progressivamente aos sistemas educacionais em nosso país.

Dadas essas considerações iniciais, o objetivo deste texto é o de apontar alguns desafios postos para formuladores e implementadores de projetos de formação, a partir de duas das várias vertentes que os subsidiam. Aborda-se inicialmente um conjunto de fatores que configura alguns aspectos do contexto no qual os projetos se realizam. Em seguida, trata-se de aclarar a relação entre a concepção da criança e seu desenvolvimento e os enfoques, ênfases e temas específicos de formação propostos.

\section{HISTÓRIA, LEIS E POLÍTICAS PÚBLICAS: CUIDAR/EDUCAR COMO PRÉ-REQUISITO}

A história não é uma única história mas o produto de muitas outras. A história da educação infantil, das suas instituições, dos seus profissionais, das crianças pequenas que se encontram nas instituições e de suas famílias, em cada uma das cidades do país está em permanente interseção com muitas outras histórias: a da infância, da família, da população, da urbanização, do trabalho, das relações de produção e das demais instituições educacio- 
nais. Nessa trajetória as instituições articulam-se, ainda, com a história da assistência, a do discurso pedagógico e a das mentalidades (Kuhlmann Jr., 1998).

Numa perspectiva histórica, identificar bebês e crianças pequenas como grupo social distinto dos adolescentes, dos jovens ou dos adultos decorre de uma configuração política, econômica e cultural, implicando o reconhecimento de características específicas dessas crianças pela sociedade como um todo. Uma das evidências desse reconhecimento é o espaço que os bebês ocupam na produção de bens culturais e de serviços a eles destinados em algumas das sociedades contemporâneas. Em nosso país as crianças desde o nascimento são objeto de legislação específica, conforme prevê a Constituição da República Federativa do Brasil' (Brasil, 1988) e o Estatuto da Criança e do Adolescente (Brasil, 1990)². Na medida em que a legislação em vigor estabelece uma série de medidas de proteção à infância, é possível afirmar que um bebê, ao ser concebido, passa a ser alguém que possui mais que um lugar na vida da mãe, do pai ou da família, tornando-se um sujeito de direitos: direito à vida, à saúde, à alimentação, à cultura, à dignidade, ao respeito, à liberdade, à convivência familiar e comunitária, ao lazer e à educação. De modo inédito, na Constituição de 1988 e no Estatuto da Criança e do Adolescente o direito à educação é explicitamente assegurado às crianças de 0 a 6 anos $^{3}$.

Reivindicar o direito à educação para crianças pequenas é uma tendência ratificada recentemente pela Lei de Diretrizes e Bases da Educação Nacional - LDB - Lei federal n. 9.394, de 20 de dezembro de 1996 - a qual reconhece a educação infantil como parte integrante do sistema educacional e determina um conjunto de medidas para regulamentação da área (Brasil, 1996). Estabelecendo a educação infantil como primeira etapa da educação básica ${ }^{4}$, a partir da promulgação dessa lei criam-se condições para que os profissionais que atuam em creches, pré-escolas e instituições similares venham a deter direitos e deveres equivalentes aos de docentes (professores) e não docentes (profissionais da admi-

I. "Todos são iguais perante a lei, sem distinção de qualquer natureza..." (Brasil, 1988, título II, capítulo I, art. 5). "São direitos sociais a educação, a saúde, o trabalho, o lazer, a segurança, a previdência social, a proteção à maternidade e à infância, a assistência aos desamparados, na forma desta Constituição" (Brasil, 1988, título II, capítulo II, art. 6). "É dever da família, da sociedade e do Estado assegurar à criança e ao adolescente, com absoluta prioridade, o direito à vida, à saúde, à alimentação, à educação, ao lazer, à profissionalização, à cultura, à dignidade, ao respeito, à liberdade e à convivência familiar e comunitária, além de colocá-los a salvo de toda forma de negligência, discriminação, exploração, violência, crueldade e opressão" (Brasil, 1988, título VIII, cap. VII, art. 227).

2. O Estatuto da Criança e do Adolescente, Lei federal n. 8.069, de 13 de julho de 1990, dispõe sobre a proteção integral à criança e ao adolescente: os direitos dessas pessoas desde o nascimento até os 18 anos de idade, bem como define as atribuições da sociedade como um todo e de suas instituições a fim de garantir o cumprimento dessas disposições.

3. "O dever do Estado com a educação será efetivado mediante a garantia de : ....atendimento em creche e préescola às crianças de zero a seis anos de idade" (Brasil, 1988, título VIII, cap. III, art. 208, inciso IV). "É dever do Estado assegurar à criança e ao adolescente... atendimento em creche e pré-escola às crianças de zero a seis anos de idade" (Brasil, 1990, cap. IV, art.54, inciso IV).

4. "A educação escolar compõe-se de: I - educação básica formada pela educação infantil, ensino fundamental e ensino médio; II - educação superior." (Brasil, I996, título V, cap. I, art. 21, incisos I e II) 
nistração, planejamento, inspeção, supervisão, coordenação e orientação educacional) vinculados a outros níveis de ensino ${ }^{5}$.

Com seu conjunto de prescrições e, especialmente, com a exigência de formação prévia e apropriada para o trabalho com crianças pequenas, a LDB legitima iniciativas no campo da educação infantil visando à recomposição do cenário no qual instituições, adultos e crianças pequenas convivem cotidianamente. $\bigcirc$ acesso de estudantes experientes ou iniciantes a cursos de formação específica é uma forma de cumprir com a exigência legal de formação. Até a promulgação da LDB, os cursos que preparavam os profissionais para atuarem nos sistemas educacionais não tinham como tarefa implícita incorporar temas relativos ao cuidado e à educação de bebês ou sobre o atendimento da criança em período integral, mesmo que eventualmente o fizessem. Doravante a exigência de profissionais com formação específica impõe-se como uma das estratégias de incorporar o atendimento a crianças na faixa etária inferior aos 4 anos dentro dos padrões de atendimento estabelecidos pelos sistemas educacionais, o que implica um retorno aos estudos do pessoal que já atua na área, porém sem habilitação específica para tanto.

Com as determinações contidas na LDB, a formação específica dos profissionais de educação infantil passa a merecer um destaque especial, tendo em vista seu caráter de prérequisito para o exercício de funções docentes e não docentes. Ademais, as prescrições legais sobre a educação infantil conduzem à inclusão de temas peculiares à formação dos que trabalham na área - tais como desenvolvimento infantil e montagem de projetos pedagógicos -, sempre tendo em mente a faixa etária que vai do nascimento aos 6 anos e o atendimento em período parcial ou integral.

Uma determinação legal adquire concretude no campo quando associada a intervenções com finalidades expressas. Nesse sentido, observa-se que concomitantemente aos avanços no plano legal iniciativas no plano político vêm se concretizando em nível nacional. A Coordenação Geral de Educação Infantil do Ministério da Educação - Coedi/ MEC - no documento Política Nacional de Educação Infantil, por exemplo, propõe a formação prévia dos profissionais da área como um elemento-chave para a melhoria da qualidade do atendimento. Indo além, esse mesmo documento associa essa premissa à função específica desses profissionais: "educar e cuidar, de forma integrada, a criança na faixa de zero a seis anos de idade" (Brasil, 1994a, p. 19).

5. No Título IV o texto legal é bastante claro quando menciona que o profissional que se ocupa diretamente das crianças na faixa etária de 0 a 6 anos é o docente da educação infantil o qual passa a deter direitos tais como: plano de carreira, piso salarial, possibilidade de licenciamento com finalidade de aperfeiçoamento profissional, progressão na carreira baseada na titulaçãa, habilitação ou avaliação, condições adequadas de trabalho e ingresso por concurso público. Chama a atenção o texto da lei quando explicita a exigência de período reservado para estudos, planejamento e avaliação, incorporados na carga horária de trabalho (art. 67). Por sua vez, a LDB expressa deveres a serem observados por esses profissionais quanto ao nível de formação exigido como pré-requisito para o exercício das diferentes funções: nível superior (graduação em Pedagogia ou curso de pós graduação), admitida a formação mínima em nível médio, na modalidade Normal (art. 64). 
Cuidar/educar crianças de 0 a 6 anos passa a ser a expressão cada vez mais utilizada para designar uma orientação compatível com o atendimento a crianças nessa faixa etária em contextos coletivos e torna-se um dos principais pré-requisitos para a ação dos profissionais de educação infantil. Essa perspectiva vem sendo reiterada em iniciativas subseqüentes da Coedi/MEC expressas em documentos oficiais nos últimos anos (Brasil, 1994, 1994a, 1994b; Brasil, 1995, 1995a; Brasil, 1996a, 1996b; Brasil, 1997).

\section{CRIANÇA PEQUENA: INTERAÇÃO SOCIAL E AMPLIAÇÃO DO UNIVERSO DE SIGNIFICADOS}

Analisando outro pilar no qual se apóiam projetos de formação para educação infantil, verifica-se que avanços no conhecimento científico respaldam teorias sobre os modos como os bebês crescem e se desenvolvem exigindo intervenções específicas por parte dos adultos responsáveis. Confere-se, cada vez mais, um destaque ao papel das interações sociais precoces na ampliação do repertório de significados pelas crianças e ao papel mediador dos educadores. Nesse sentido, a formação específica exigida na LDB expressa uma consonância da lei com um movimento mais amplo no campo da educação infantil. Se há tempos atrás o profissional leigo, paciente e afetivo satisfazia a expectativa social para a função de cuidar das crianças pequenas enquanto suas mães estavam trabalhando, a exigência de um docente especialmente qualificado e com nível de escolaridade mais elevado vem responder ao clamor de democratização da educação e de melhoria da qualidade do atendimento (Campos, 1997), argumentos que se potencializam quando associados ao reconhecimento do especial valor das interações de bebês e crianças pequenas com adultos e companheiros de mesma idade, maiores ou menores, em contextos coletivos de boa qualidade.

Conceber a criança como ser interativo implica advogar que essa criança desde que nasce é competente para interagir no meio em que se encontra (Bondioli, Mantovani, 1989; Davis, Oliveira, 1990; Souza, Kramer, 1991; Myers, 1991; Oliveira, 1992, Oliveira, 1994; Oliveira, Rossetti-Ferreira, 1993; Machado, 1993, Machado, 1994; Campos, 1994; Davis, 1994). Entretanto, a interação a que se referem esses autores não é uma interação qualquer, de modo genérico. Trata-se de interação social, um processo que se dá a partir e por meio de indivíduos com modos historicamente determinados de agir, pensar e sentir (Davis, 1994).

Na perspectiva das interações sociais parece plausível deduzir que quanto maior a diversidade de parceiros e experiências, potencialmente mais enriquecido torna-se o desenvolvimento infantil. Crianças expostas desde bebês a uma gama ampliada de possibilidades interativas têm seu universo pessoal ampliado, observando-se competências precoces para superar o egocentrismo e desenvolver uma autonomia diante do adulto. A imitação, as trocas, o jogo cooperativo, a atenção seletiva, a intencionalidade comunicativa e a cons- 
trução de significados compartilhados são alguns dos exemplos de adaptação da conduta entre crianças que freqüentam creches e pré-escolas de boa qualidade desde muito pequenas (Bondioli e Mantovani, 1989).

Cabe ressalvar, entretanto, que a ampliação das experiências infantis nem sempre se dá em um sentido positivo, ou seja, de modo a beneficiar a criança. Experiências envolvendo violência ou simples ameaça, por exemplo, também ampliam o repertório infantil, só que de forma negativa e danosa. A educação infantil em instituições coletivas tem como uma de suas tarefas promover a aprendizagem progressiva de significados compartilhados na vida em comum (Rossignol, Hirt, 1996) em uma perspectiva positiva de avanços e de ampliações em matéria de competências e conhecimentos. Cabe ao adulto, ainda, a articulação de atividades previamente selecionadas e aprendizagens progressivamente mais abrangentes e consistentes com experiências inéditas para as crianças.

\section{PROJETOS DE FORMAÇÃO: DESAFIOS IMINENTES}

Diante da necessidade de compatibilizar enfoques, ênfases e temas de formação, alguns desafios decorrentes das análises apresentadas são considerados iminentes formuladores e implementadores de projetos de formação para educação infantil. Um deles refere-se à tarefa de integrar o enfoque no cuidar/educar, dando ênfase numa pedagogia calcada nas interações de crianças e adultos.

Como bem observou Campos (1994), essa perspectiva exige um novo tipo de atuação dos profissionais baseada na não-hierarquização das atividades e na não-segmentação dos espaços, horários e responsabilidades dos diferentes profissionais envolvidos. Parte-se de uma concepção que situa a criança tanto no contexto social, ambiental, cultural amplo, quanto no contexto das interações que estabelece com os adultos e outras crianças (Rosemberg, Campos, 1996). É a mediação dos adultos com os quais a criança interage que viabiliza a apropriação de significados que, por sua vez, levam à construção da identidade, do desenvolvimento moral e da consciência de si, alterando sua percepção de mundo. A postura ideal do adulto encontra-se na mescla de garantir o respeito às necessidades e interesses da criança, os padrões e valores da cultura e da sociedade em que ela se encontra e ampliar permanentemente as fronteiras de seu universo.

Pesquisadoras francesas (Hardy, Platone, Stambak, 199I), por exemplo, afirmam que as crianças antes mesmo de se expressarem pela linguagem verbal são capazes de desenvolver raciocínios lógicos e exprimir relações complexas, desde que acompanhadas por iniciativas específicas dos adultos, tais como: apoiar a organização das crianças em pequenos grupos; incentivar a colaboração; dar-lhes tempo para desenvolver temas de trabalho a partir de propostas prévias; intervir para trazer um elemento de conhecimento novo dentro da temática desenvolvida ou estimular as trocas entre os parceiros. Essas iniciativas dos adultos favorecem a intenção comunicativa das crianças pequenas e o inte- 
resse de uns pelos outros, o que faz com que aprendam a se perceber e a levar em conta os pontos de vista dos outros, permitindo a circulação das idéias, a complementação ou a resistência às iniciativas dos parceiros. Essa última, por sua vez, incita à própria argumentação, à objetivação do pensamento e ao recuo reflexivo da criança.

Nessas circunstâncias os objetos de investigação de bebês e crianças pequenas tomam formas e direções inesperadas. Uma pedagogia voltada para as interações de crianças pretende romper com modos tradicionais de organização da prática pedagógica, tendo em vista, por exemplo, que uma das prioridades incide na livre expressão das crianças. A sua comunicação não só é autorizada como incentivada. Cabe ao professor interferir para trazer elementos novos, apoiar e validar, ou não, as argumentações e iniciativas das crianças.

A prática da observação participante pelos adultos é outro ponto nodal de uma pedagogia voltada para as interações infantis, implicando uma atitude de pesquisa cotidiana. Definem-se como características da organização das situações educativas para crianças a partir dos 4 meses: a organização das atividades em pequenos grupos (de dois a cinco elementos); a seleção de diferentes tipos de materiais em razão dos objetivos que se têm em mente; a organização do tempo de modo flexível; a inserção dos adultos, de modo a captar as formas e os motivos de atuação das crianças. Enfatizam-se as necessidades de desenvolvimento dos bebês e das crianças bem pequenas, as interações infantis e os jogos de descoberta, evitando determinar-se uma organização rígida do tempo e dos espaços (Hardy, Platone, Stambak, 1991; Rayna et al., 1991; Ghedini, 1992).

Outro desafio crucial a ser enfrentado pelos responsáveis por projetos de formação para educação infantil é o de configurar propostas de atendimento específicas para crianças de 0 a 6 anos. Quando se retoma o percurso recente da área, relembra-se que, na década de 80, uma das ambições mais fortes entre militantes do campo da educação infantil no Brasil era a extensão do direito à educação para todas as crianças na faixa etária de 0 a 6 anos. Como foi dito, essa pretensão, conquistada com a Constituição de 1988 e ratificada pelo Estatuto da Criança e do Adolescente em 1990, é finalmente referendada na LDB em 1996.

Idealmente a incorporação das creches, pré-escolas e instituições similares pelos sistemas educacionais foi vista como sendo um passo estratégico a ser dado a fim de garantir a melhoria da qualidade do atendimento às crianças pequenas. Todavia, para que esse encaminhamento tenha os efeitos almejados, é preciso que esteja muito claro em que a educação infantil, como primeira etapa da educação básica, se distingue, ou não, das fases que a sucedem. Alerta-se para o fato de que, ao se incluir instituições de atendimento a crianças de 0 a 6 anos no sistema escolar formal, é uma concepção global de educação - a da importância do jogo e da criatividade, da aquisição de conhecimentos, da abertura das estruturas informais e da descentralização em direção à família e à comunidade, da participação intensa dos pais e do respeito à diversidade local - que se coloca em risco (Oberhuemer, Ulich, 1996). 
Sabendo da força com que um modelo de escolarização caricato vem se difundindo nas instituições de atendimento a crianças de 0 a 6 anos (Brasil, 1996b) mais do que nunca é preciso buscar inspiração em propostas de atendimento sustentadas em aportes teóricos consistentemente fundamentados nas necessidades e características de crescimento e desenvolvimento de bebês e crianças pequenas. A percepção de o quanto esse estereótipo vem impactando profissionais, mães, pais e as próprias crianças é confirmada, por exemplo, pelo uso corrente da denominação "escolinha" para identificar uma creche ou préescola.

Desejar a incorporação do atendimento às crianças pequenas aos sistemas educacionais não pode vir a significar apenas herdar e incorporar as mazelas desses sistemas. A rigidez dos horários, do calendário letivo ou das programações, os tradicionais processos de avaliação utilizados e o conseqüente favorecimento das crianças tidas como mais aptas e a exclusão das tidas como menos competentes, são situações inadmissíveis nas propostas de atendimento voltadas a bebês e crianças pequenas.

No plano dos desafios é preciso sublinhar o fato de que, nesse final de século e de milênio, a trajetória histórica da educação infantil passa por um momento de inflexão, em face da incorporação desse campo pelos sistemas nacionais de educação, na condição de primeira etapa da educação básica. Com essa medida, instituiç̧̃̃es, profissionais, mantenedores, órgãos administrativos e normativos que atuam no nível do ensino fundamental e médio, juntamente com aqueles presentes no nível da educação infantil, passam a integrar uma única etapa educacional, a da educação básica, passando a constituir uma nova história.

Do ponto de vista de docentes e não docentes que pertençam aos quadros de profissionais da educação básica, essa nova situação pode representar tanto uma ampliação do mercado de trabalho quanto uma sobrecarga nas tarefas que executam. Para uma secretaria de educação, por exemplo, passar a se preocupar com a situação das creches de seu município pode representar um acréscimo de trabalho e de problemas, tendo em vista que as dificuldades que enfrentará se somarão àquelas advindas do ensino fundamental.

Um agravante para essa situação é o fato de existir uma rica e diversificada trajetória histórica construída no campo da educação infantil no Brasil nas diferentes regiões e localidades, trajetória que, por sua vez, permitiu a construção de um acervo de conhecimentos que não são, necessariamente, conhecidos e compartilhados com docentes e não docentes de outros níveis ou sistemas de ensino. Isso significa que, doravante, os profissionais da educação básica, especialmente os que atuam em nível técnico, devem forçosamente dominar essa área de conhecimentos, sob pena de não responderem de modo adequado às expectativas que se colocam.

Impossível prever, todavia, como se dará essa apropriação, visto que o que é bom para o ensino fundamental nem sempre é transferível para a educação infantil, especialmente quando se trata do atendimento a bebês e crianças muito pequenas em período 
integral. Mesmo admitindo que os conhecimentos adequados venham a ser adquiridos e consolidados em breve, é preciso prever um período de transição no qual será necessário, mais do que nunca, que os profissionais da educação infantil tenham claro qual o encaminhamento apropriado para as propostas de atendimento institucional pautadas na integração educar/cuidar de crianças de 0 a 6 anos.

As instituições de educação infantil, seus profissionais, as crianças pequenas e suas famílias encontram-se às portas de ingresso nos sistemas educacionais em nosso país, integrando-se à história de suas instituições e de seus profissionais, com direito a contradições e a desafios. Resta saber se nesse processo de incorporação predominarão tendências advindas do próprio campo da educação infantil, de interesses que the são estranhos ou, ainda, se uma terceira combinação resultará de uma recomposição equivalente de forças.

O momento histórico que o campo do atendimento às crianças de 0 a 6 anos vive é delicado. Diante de propostas que reforçam práticas avaliativas e excludentes, direcionadas até mesmo aos bebês, é preciso uma mobilização intensa do setor com vistas a impedir que se concretizem iniciativas nessa direção.

Reivindicar uma formação específica para os profissionais não pode significar, portanto, um preparo para copiar o modelo da escola de ensino fundamental, mas sim para captar as especificidades do trabalho com crianças de 0 a 6 anos, solidificando uma história que ainda engatinha mesmo em países mais evoluídos social e economicamente que o nosso.

"A história é algo muito forte", é o que afirma Watterson ( 991 ), na voz da personagem criança Calvin. Na seqüência dos quadrinhos o garoto acompanha essa afirmação com argumentos para justificar sua existência para Haroldo, seu fiel companheiro, que contrapõe esses argumentos afirmando que 4,5 bilhões de anos não foram suficientes para que o produto final da história fosse satisfatório. A história das crianças pequenas e de suas famílias, das instituições que delas se ocupam e dos profissionais que junto a elas atuam continuará a ser escrita por militantes, pesquisadores, professores, políticos, técnicos e por cada um dos leitores deste texto.

\section{REFERÊNCIAS BIBLIOGRÁFICAS}

APPLE, M. W. Repensando Ideologia e currículo. In: MOREIRA, A. F., SILVA, T. T. Currículo, cultura e sociedade. São Paulo: Cortez, 1994. p.39-57.

BONDIOLI, A., MANTOVANI, S. (org.). Manuale crítico dell'asilo nido. Milão: Franco Angeli, 1989.

BRASIL. Câmara dos Deputados. $\angle D B / L$ ei de Diretrizes e Bases da Educação Nacional. Brasília: Secretaria Especial de Informação e Publicações, 1996.

BRASIL. Governo. Constituição da República Federativa do Brasil. São Paulo: Tecnoprint, 1988. 
Estatuto da Criança e do Adolescente. Brasília: Imprensa Nacional, 1990.

BRASIL. Ministério da Educação e do Desporto. Secretaria de Educação Fundamental. Anais do / Simpósio Nacional de Educação Infantil. Brasilia: MEC/SEF/DPE/COEDI, 1994.

. Anais do // Simpósio Nacional de Educação Infantil. Brasilia: MEC/SEF/DPEF/COEDI, 1996a.

. Critérios para um atendimento em creches que respeite os direitos fundamentais das crianças. Brasilia: MEC/SEF/DPE/COEDI, 1995.

Educação Infantil: bibliografia anotada. Brasília: MEC/SEF/DPE/COEDI, 1995a.

Política nacional de educação infantil. Brasilia: MEC/SEF/DPE/COEDI, I994a.

. Por uma política de formação do profissional de educação infantil. Brasília: MEC/ SEF/DPE/COEDI, 1994b.

Propostas pedagógicas e currículo em educação infantil. um diagnóstico e a construção de uma metodologia de análise. Brasília: MEC/SEF/DPEF/COEDI, 1996b.

Subsídios para elaboração de critérios para credenciamento e funcionamento de instituições de educação infantil. Brasilia: MEC/SEF/DPEF/COEDI, 1997. (versão preliminar)

CAMPOS, M. M. Educação infantil: o debate e a pesquisa. Cadernos de Pesquisa. São Paulo, n. I0I, p. I |3-27, jul. 1997.

Educar e cuidar: questões sobre o perfil do profissional de educação infantil. In: BRASIL. Ministério da Educação e do Desporto, Secretaria de Educação Fundamental. Por uma política de formação do profissional de educação infantil. Brasilia: MEC/SEF/DPE/COEDI, 1994. p.32-42.

DAVIS, C. O Construtivismo de Piaget e o sócio-interacionismo de Vygotski. São Paulo, 1994. mimeo.

DAVIS, C., OLIVEIRA, Z. M. R. Psicologia na educação. São Paulo: Cortez, 1990.

DOMINGUES, J. L. O Cotidiano da escola de 10 grau: o sonho e a realidade. Goiânia: CEGRAF/ UFG; São Paulo: EDUC, 1988.

EVANS, E. D. Curriculum models and early childhood education. In: SPODECK, B. (org.). Handbook of research in early childhood education. N. York: The Free Press, 1982. p. 107-34.

GHEDINI, P. La Politique sociale de la petite enfance en Italie. In: PIERREHUMBERT, B. (org.). L'accueil du jeune enfant. politiques et recherches dans les différents pays. Paris: ESF, 1992. p.89-97. 
HARDY, M., PLATONE, F., STAMBAK, M. Naissance d'une pédagogie interactive. Paris: CRESAS/ ESF/NRP, | 991 .

KUHLMANN JR., M. Infância e educação infantil: uma abordagem histórica. Porto Alegre: Mediação, 1998.

MACHADO, M. L. Educação infantil e currículo. Caxambu, 1996. (Trabalho apresentado na $19^{a}$ Reunião Anual da ANPEd)

In: BRASIL. Ministério da Educação e do Desporto. Secretaria de Educação Fundamental. Propostas pedagógicas e currículo em educação infantil: um diagnóstico e a construção de uma metodologia de análise. Brasília : MEC/SEF/DPEF/COEDI, $1996 a$.

Educação infantil e paradigmas. da criança ativa à criança interativa. Caxambu, 1994. (Trabalho apresentado na 17 a ANPEd)

. Educação infantil e sócio-interacionismo. In: OLIVEIRA, Z. M. R. Educação infantik: muitos olhares. São Paulo: Cortez, 1994a, p.25-50.

Exclamações, interrogações e reticências na instituição de educação infantit: uma análise a partir da teoria sócio-interacionista de Vygotski. São Paulo, 1993. Dissert. (mestr.) PUC/SP.

Formação e valorização do profissional de educação infantil. In: BRASIL. Ministério da Educação e do Desporto. Secretaria de Educação Fundamental. ANAIS do // Simpósio Nacional de Educação Infantil. Brasília: MEC/SEF/DPE/COEDI, I996b.

Formação profissional para educação infantit. subsídios para idealização e implementação de projetos. São Paulo, 1998. Tese (dout.) PUC/SP.

A. Pré-escola é não é escola. São Paulo: Paz e Terra, I991.

Proposta de critérios de análise e avaliação de projetos educacionais-pedagógicos para a educação infantil no Brasil. São Paulo, 1994b. mimeo.

MOREIRA, A. F. B. Currículos e programas no Brasil. Campinas: Papirus, 1995.

MOREIRA, A. F., SILVA, T. T. (orgs.). Currículo, cultura e sociedade. São Paulo: Cortez, 1994.

MYERS, R. G. Um tempo para a infância: os programas de intervenção precoce no desenvolvimento infantil nos países em desenvolvimento. Porto: Unesco, 1991.

OBERHUEMER P., ULICH, M. Les Personnels de la petite enfance: types de formations et offre d'accueil dans les pays de l'Union Européenne. In: RAYNA, S., LAEVERS, F., DELEAU, M. (org.). L'Éducation préscolaire: quels objectifs pédagogiques? Paris: INRP-Natham, 1996. p.33-50. 
OLIVEIRA, Z. M. R. Didática e construtivismo. Goiânia, 1994. (Trabalho apresentado no VII Encontro Nacional de Didática e Prática de Ensino)

Rediscutindo a natureza do ensino. In: SOARES, M. B. et al. Escola básica. Campinas: Papirus, Cedes; São Paulo: ANPEd, Ande, 1992, p.63-9.

OLIVEIRA, Z. M. R., ROSSETTI-FERREIRA, M. C. O Valor da interação criança-criança em creches no desenvolvimento infantil. Cadernos de Pesquisa, n. 87, p.62-70, nov. 1993.

RAYNA, S. et al. Dans les crèches et les jardins d'enfants: interactions sociales et construction des connaissances. In: HARDY, M., PLATONE, F., STAMBAK, M. Naissance d'une pédagogie interactive. Paris: CRESAS/ESF/INRP, I991 . p.21-37.

ROSEMBERG, F., CAMPOS, M. M. Subsídios para a elaboração de propostas e de regulamentação para a formação profissional do educador de creche. In: BELO HORIZONTE. Secretaria de Educação. Proposta ao Conselho Estadual de Educação de Minas Gerais para criação de curso regular para qualificação profissional (nível de $1{ }^{\circ}$ grau) do educador infantil de creche/similar, integrado a curso supletivo de ensino fundamental (5 a $8^{a}$ série). Belo Horizonte, 1996. p.47-77.

ROSSETTI-FERREIRA, M. C. Tornar-se humano. Infância na ciranda da educação. Belo Horizonte: CAPE/SMED, n.3, p.29-33, 1997.

ROSSIGNOL, F., HIRT, A. Enseigner à l'école maternelle. In: AUGEARD, M.-C. et al. L'École maternelle aujourd'hui: réflexions et témoignages: des idées pour innover. Paris: Retz, 1996.

SOUZA, S. J., KRAMER, S. O Debate PiagetNygotsky e as políticas educacionais. Cadernos de Pesquisa, n.77, p.69-81, maio 1991.

WATtERSON, B. O Progresso científico deu "tilt". São Paulo: Best, 1991. 